\title{
Short communication: Prediction of milk coagulation and acidity traits in Mediterranean buffalo milk using Fourier-transform mid-infrared spectroscopy
}

\author{
C. L. Manuelian, ${ }^{*}$ G. Visentin, ${ }^{*}$ C. Boselli, $\dagger$ G. Giangolini, $†$ M. Cassandro, ${ }^{*}$ and M. De Marchi ${ }^{* 1}$ \\ ${ }^{*}$ Department of Agronomy, Food, Natural Resources, Animals and Environment (DAFNAE), University of Padova, Viale dell'Università 16, \\ 35020 Legnaro (PD), Italy \\ †Experimental Zooprophylactic Institute Lazio and Toscana "Mariano Aleandri," Via Appia Nuova 1411, 00178 Rome, Italy
}

\begin{abstract}
Milk coagulation and acidity traits are important factors to inform the cheesemaking process. Those traits have been deeply studied in bovine milk, whereas scarce information is available for buffalo milk. However, the dairy industry is interested in a method to determine milk coagulation and acidity features quickly and in a cost-effective manner, which could be provided by Fourier-transform mid-infrared (FT-MIR) spectroscopy. The aim of this study was to evaluate the potential of FT-MIR to predict coagulation and acidity traits of Mediterranean buffalo milk. A total of 654 records from 36 herds located in central Italy with information on milk yield, somatic cell score, milk chemical composition, milk acidity [pH, titratable acidity (TA)], and milk coagulation properties (rennet coagulation time, curd firming time, and curd firmness) were available for statistical analysis. Reference measures of milk acidity and coagulation properties were matched with milk spectral information, and FT-MIR prediction models were built using partial least squares regression. The data set was divided into a calibration set $(75 \%)$ and a validation set (25\%). The capacity of FT-MIR spectroscopy to correctly classify milk samples based on their renneting ability was evaluated by a canonical discriminant analysis. Average values for milk coagulation traits were $13.32 \mathrm{~min}, 3.24 \mathrm{~min}$, and $39.27 \mathrm{~mm}$ for rennet coagulation time, curd firming time, and curd firmness, respectively. Milk acidity traits averaged 6.66 $(\mathrm{pH})$ and 7.22 Soxhlet-Henkel degrees/100 mL (TA). All milk coagulation and acidity traits, except for $\mathrm{pH}$, had high variability (17 to $46 \%$ ). Prediction models of coagulation traits were moderately to scarcely accurate, whereas the coefficients of determination of
\end{abstract}

Received February 10, 2017.

Accepted May 5, 2017.

${ }^{1}$ Corresponding author: massimo.demarchi@unipd.it external validation were 0.76 and 0.66 for $\mathrm{pH}$ and $\mathrm{TA}$, respectively. Canonical discriminant analysis indicated that information on milk coagulating ability is present in the MIR spectra, and the model correctly classified as noncoagulating the 91.57 and $67.86 \%$ of milk samples in the calibration and validation sets, respectively. In conclusion, our results can be relevant to the dairy industry to classify buffalo milk samples before processing.

Key words: buffalo cheese, mid-infrared spectrometry, milk coagulation property, milk quality

\section{Short Communication}

In the last $10 \mathrm{yr}$, the buffalo (Bubalus bubalis) population has increased worldwide, and Italy represents, mainly in the central and southern regions, approximately the $80 \%$ of the total population in Europe (FAOSTAT, 2017). Buffalo milk is the second most produced milk after bovine milk, representing $14 \%$ of the global production in 2014 (FAOSTAT, 2017). Moreover, buffalo milk is richer than bovine milk for almost all the major constituents (Zicarelli, 2004; Abd El-Salam and El-Shibiny, 2011). In Italy, as well as in other European countries, buffalo milk is almost completely used for manufacturing different types of cheese (Zicarelli, 2004; Manuelian et al., 2017), particularly Mozzarella, but also to a lesser extent various type of fresh and ripened cheeses (Tripaldi et al., 2013). Consequently, milk coagulation traits (McMahon and Brown, 1982), namely rennet coagulation time (RCT), curd firming time $\left(\mathbf{k}_{\mathbf{2 0}}\right)$, curd firmness 30 min after rennet addition to milk $\left(\mathbf{a}_{\mathbf{3 0}}\right)$, and acidity $[\mathrm{pH}$ and titratable acidity $(\mathbf{T A})]$, are important factors informing milk processability for the cheesemaking process. Determination of these traits is time-consuming, expensive, requires different analytic instruments, and does not allow on-field application for large data assessment. Several nongenetic factors, such as stage of lactation, parity, feeding strategies, and udder health, are associated with variation of buffalo 
Table 1. Descriptive statistics of Mediterranean buffalo milk composition and technological traits after editing

\begin{tabular}{|c|c|c|c|c|c|}
\hline Trait $^{1}$ & $\mathrm{~N}$ & Mean & $\mathrm{SD}$ & Range $^{2}$ & $\mathrm{CV}, \%$ \\
\hline \multicolumn{6}{|c|}{ Milk coagulation traits } \\
\hline $\mathrm{RCT}, \min$ & 538 & 13.33 & 6.12 & 27.70 & 45.90 \\
\hline $\mathrm{k}_{20}, \min$ & 467 & 3.17 & 1.23 & 7.45 & 38.91 \\
\hline $\mathrm{a}_{30}, \mathrm{~mm}$ & 540 & 39.52 & 14.91 & 61.90 & 37.73 \\
\hline \multicolumn{6}{|l|}{ Milk acidity } \\
\hline $\mathrm{pH}$ & 642 & 6.67 & 0.20 & 1.07 & 3.06 \\
\hline $\mathrm{TA}, \mathrm{SH}^{\circ} / 100 \mathrm{~mL}$ & 643 & 7.15 & 1.23 & 6.60 & 17.23 \\
\hline \multicolumn{6}{|c|}{ Milk yield and composition } \\
\hline Milk yield, kg/d & 616 & 7.11 & 3.22 & 17.74 & 45.36 \\
\hline Fat, $\%$ & 650 & 7.70 & 2.35 & 13.96 & 30.48 \\
\hline Protein, $\%$ & 650 & 4.76 & 0.58 & 7.79 & 12.18 \\
\hline Casein, \% & 650 & 3.65 & 0.55 & 6.98 & 15.07 \\
\hline Lactose, \% & 650 & 4.60 & 0.66 & 4.27 & 14.40 \\
\hline SCS & 649 & 5.15 & 0.58 & 3.35 & 11.16 \\
\hline
\end{tabular}

milk composition (Zicarelli, 2004; Abd El-Salam and El-Shibiny, 2011).

Fourier-transform mid-infrared (FT-MIR) spectroscopy is routinely used to rapidly determine at a costeffective traditional milk composition, such as concentrations of protein, fat, and lactose, but also innovative bovine milk quality (De Marchi et al., 2014) and animal (Bastin et al., 2016; McParland and Berry, 2016) characteristics. However, to our knowledge no studies have investigated the potential of FT-MIR spectroscopy to predict coagulation and acidity traits of buffalo milk. Prediction equations of milk technological traits in cow milk demonstrated their potential application, achieving a ratio of prediction to deviation (RPD) in some cases close to 2 (De Marchi et al., 2009; Toffanin et al., 2015; Calamari et al., 2016; Visentin et al., 2016), which is the generally accepted threshold after which a prediction model could be considered sufficient (Williams, 2007). In addition, FT-MIR prediction models of bovine milk coagulation traits are repeatable but not highly reproducible (Penasa et al., 2015). The aim of the present study was to assess the potential prediction of milk coagulation and acidity traits of buffalo dairy cattle through FT-MIR spectroscopy.

A total of 654 individual milk samples $(60 \mathrm{~mL}$ without preservative) of Mediterranean Italian buffaloes were collected from October 2014 to March 2015 during test-day recording in 36 herds located in central Italy. Individual test-day milk yield was also registered using 3 electronic mobile milk flow meters (LactoCorder, WMB, Balgach, Switzerland). Milk samples were transported refrigerated $\left(4^{\circ} \mathrm{C}\right)$ to the Istituto Zooprofilattico Sperimentale del Lazio e della Toscana (Rome, Italy) within 24 to $36 \mathrm{~h}$ of collection for milk chemical composition, SCC, milk acidity, and milk coagulation traits determination (Table 1). Briefly, $\mathrm{pH}$ was determined using a potentiometric pHmeter (Mettler Delta 345; Mettler Toledo SpA, Novate Milanese, Italy) and TA was recorded as Soxhlet-Henkel degrees $\left(\mathbf{S H}^{\circ}\right)$ using a Crison Compact D meter (Crison Instruments SA, Alella, Spain) by titrating milk with a $\mathrm{NaOH} 0.25 \mathrm{~N}$ solution until a $\mathrm{pH}$ of 8.30 . Milk coagulation traits were assessed by Formagraph (Foss Electric, Hillerød, Denmark); milk samples $(10 \mathrm{~mL})$ were heated to $35^{\circ} \mathrm{C}$ and $200 \mu \mathrm{L}$ of calf rennet Clerici $(25 \%$ chymosin and $75 \%$ pepsin; Sacco rsl, Cadorago, Italy) diluted to $1 \%$ (wt/ wt) in distilled water was added to milk. Measurement ended at $30 \mathrm{~min}$ after the addition of the enzyme. Fat, protein, casein, and lactose content was determined by MilkoScan FT6000 (Foss Electric) calibrated with appropriate buffalo standards.

Spectral information of milk samples containing 1,060 data points in the region between 5,000 and $900 \mathrm{~cm}^{-1}$, were obtained by MilkoScan FT6000 (Foss Electric) and they were matched with their reference values for RCT, $\mathrm{k}_{20}, \mathrm{a}_{30}, \mathrm{pH}$, and TA. Somatic cell count was determined using Fossomatic FC (Foss Electric). Spectral regions between 3,690 and 2,990 $\mathrm{cm}^{-1}$ and between 1,680 and $1,580 \mathrm{~cm}^{-1}$, characterized by low signal-to-noise ratio, were discarded before statistical analysis. Values of milk coagulation or acidity traits that deviated more than 3 standard deviations from the mean of each respective trait were considered as outliers. Prediction models were developed using partial least squares regression in SAS ver. 9.4 (SAS Institute Inc., Cary, NC). The data set was divided into a calibration set $(75 \%$ of the total observations for each measured trait) and a validation set $(25 \%$ of the total observations for each measured trait). The optimal number of models factors $(\# \mathbf{L})$ was determined as the minimum number of factors to achieve the lowest root mean predicted residual sum of squares. The goodness-of-fit statistics considered were 
the coefficient of determination of cross and external validation $\left(\mathbf{R}^{2}{ }_{\mathbf{C V}}\right.$ and $\mathbf{R}_{\mathbf{E x V}}^{2}$, respectively) and the standard error of prediction of cross and external validation. In the validation set, RPD was calculated as the ratio between the standard deviation of the trait and the standard error of prediction of external validation (Williams, 2007), and bias was calculated as the average difference between the reference value and the respective predicted value for each observation. Moreover, in the validation set, reference values of each model were linearly regressed on the respective predicted value to obtain the linear regression coefficient (slope). A $t$-test was used to determine whether the bias and slope were statistically different from zero and one, respectively. For the purpose of evaluating the discriminant capacity of FT-MIR spectroscopy, the data set was stratified into 4 classes based on samples RCT defined as earlycoagulating ( $\mathrm{RCT}<10 \mathrm{~min}$ ), mid-coagulating (10 min $\leq \mathrm{RCT} \leq 20 \mathrm{~min})$, late-coagulating $(20 \mathrm{~min}<\mathrm{RCT} \leq$ $30 \mathrm{~min}$ ), and noncoagulating (milk that not coagulated after 30 min of the addition of the enzyme). Canonical discriminant analysis (CDA) was then performed on the calibration set and validated on the validation data set.

Descriptive statistics of data set are in Table 1. Average RCT agreed with Ariota et al. (2007); Cecchinato et al. (2012), whereas higher values (up to $22 \mathrm{~min}$ ) have been reported by Barile et al. (2007) and Liotta et al. (2015). Mean $\mathrm{k}_{20}$ reported by Liotta et al. (2015) were similar to results of the present study; nevertheless, lower $\mathrm{k}_{20}$ was documented by Ariota et al. (2007; 1.73 min) and Barile et al. (2007; 2.12 min). Mean $\mathrm{a}_{30}$ and $\mathrm{pH}$ were in agreement with the literature (Ariota et al., 2007; Barile et al., 2007; Cecchinato et al., 2012; Liotta et al., 2015). Greater buffalo milk TA $\left(18 \mathrm{SH}^{\circ} / 100\right.$ $\mathrm{mL}$ ) has been reported by Liotta et al. (2015); however, comparisons regarding MCP should be considered carefully because of the differences on rennet solution characteristics (e.g., a higher proportion of chymosin and greater dilution, $63 \%$ chymosin and $37 \%$ pepsin and dilution of $1.6 \%$ wt/wt; Cecchinato et al., 2012). Results of buffalo milk composition were consistent with previous studies (Ariota et al., 2007; Barile et al., 2007; Abd El-Salam and El-Shibiny, 2011; Liotta et al., 2015). A greater variation was observed for milk coagulation than for milk acidity traits. A lower variability for $\mathrm{RCT}(32 \%), \mathrm{a}_{30}(27 \%)$, and $\mathrm{pH}(2 \%)$ have been reported (Cecchinato et al., 2012).

Fitting statistics of the predicted models are in Table 2. The proportion of outliers detected was $1 \%$ for RCT and $2 \%$ for the remaining coagulation and acidity traits. For all traits, the bias in the validation set did not differ from zero $(P>0.05)$, whereas the slope of the linear regression of predicted on measured values differed from unity $(P<0.05)$. The greatest $\mathrm{R}_{\text {ExV }}^{2}$ was obtained for milk $\mathrm{pH}(0.76)$ followed by milk TA (0.66). Regarding CDA, results indicated that first and second canonical variables explained 58 and $25 \%$ of the total variation, respectively. Squared Mahalanobis distance between clusters centroids was the lowest between adjacent RCT classes. For instance, it was 37.32 between noncoagulating and early-coagulating clusters centroids, whereas it was 9.95 between mid-coagulating and early-coagulating clusters centroids. Distance between late-coagulating and noncoagulating clusters centroids was 23.88. Specificity of the prediction equation was higher for the calibration than for the validation set. Early-coagulating (calibration set, $92.00 \%$; validation set, $60.98 \%$ ) and noncoagulating (calibration set, $91.57 \%$; validation set, $67.86 \%$ ) RCT groups had the highest number of observations correctly classified. On the contrary, mid- (calibration set, $88.89 \%$; validation set, $44.4 \%$ ) and late-coagulating (calibration set, $95.45 \%$; validation set, $26.09 \%$ ) groups achieved the lowest specificity.

To our knowledge, no other studies regarding the use of FT-MIR spectroscopy to predict coagulation and acidity traits in buffalo milk are currently available.

Table 2. Fitting statistics ${ }^{1}$ of prediction models for technological traits (mean of 4 iterations) for Mediterranean buffalo milk using Fouriertransform mid-infrared (FT-MIR) spectroscopy ${ }^{1}$

\begin{tabular}{|c|c|c|c|c|c|c|c|c|}
\hline Trait $^{2}$ & \multicolumn{3}{|c|}{ Calibration set } & \multicolumn{5}{|c|}{ Validation set } \\
\hline $\mathrm{RCT}, \min$ & 14 & 4.54 & 0.45 & -0.006 & $0.38(0.05)$ & 5.17 & 0.31 & 1.19 \\
\hline $\mathrm{a}_{30}, \mathrm{~mm}$ & 17 & 10.38 & 0.51 & 0.131 & $0.45(0.05)$ & 12.43 & 0.35 & 1.20 \\
\hline $\mathrm{pH}$ & 14 & 0.09 & 0.80 & 0.003 & $0.78(0.04)$ & 0.10 & 0.76 & 2.08 \\
\hline $\mathrm{TA}, \mathrm{SH}^{\circ} / 100 \mathrm{~mL}$ & 18 & 0.64 & 0.73 & -0.023 & $0.69(0.04)$ & 0.72 & 0.66 & 1.71 \\
\hline
\end{tabular}

${ }^{1} \mathrm{HL}=$ optimal number of models factors; $\mathrm{SEP}_{\mathrm{CV}}=$ standard error of prediction of cross-validation; $\mathrm{R}_{\mathrm{CV}}^{2}=$ coefficient of determination of crossvalidation; $\mathrm{SEP}_{\mathrm{ExV}}=$ standard error of prediction of external validation; $\mathrm{R}_{\mathrm{ExV}}^{2}=$ coefficient of determination of external validation; $\mathrm{RPD}=$ ratio of prediction to deviation calculated as the ratio between the standard deviation of the trait and the $\mathrm{SEP}_{\mathrm{ExV}}$.

${ }^{2} \mathrm{RCT}=$ rennet coagulation time; $\mathrm{k}_{20}=$ curd firming time; $\mathrm{a}_{30}=$ curd firmness 30 min after rennet addition to milk; TA $=$ titratable acidity; $\mathrm{SH}^{\circ}=$ Soxhlet-Henkel degree. 


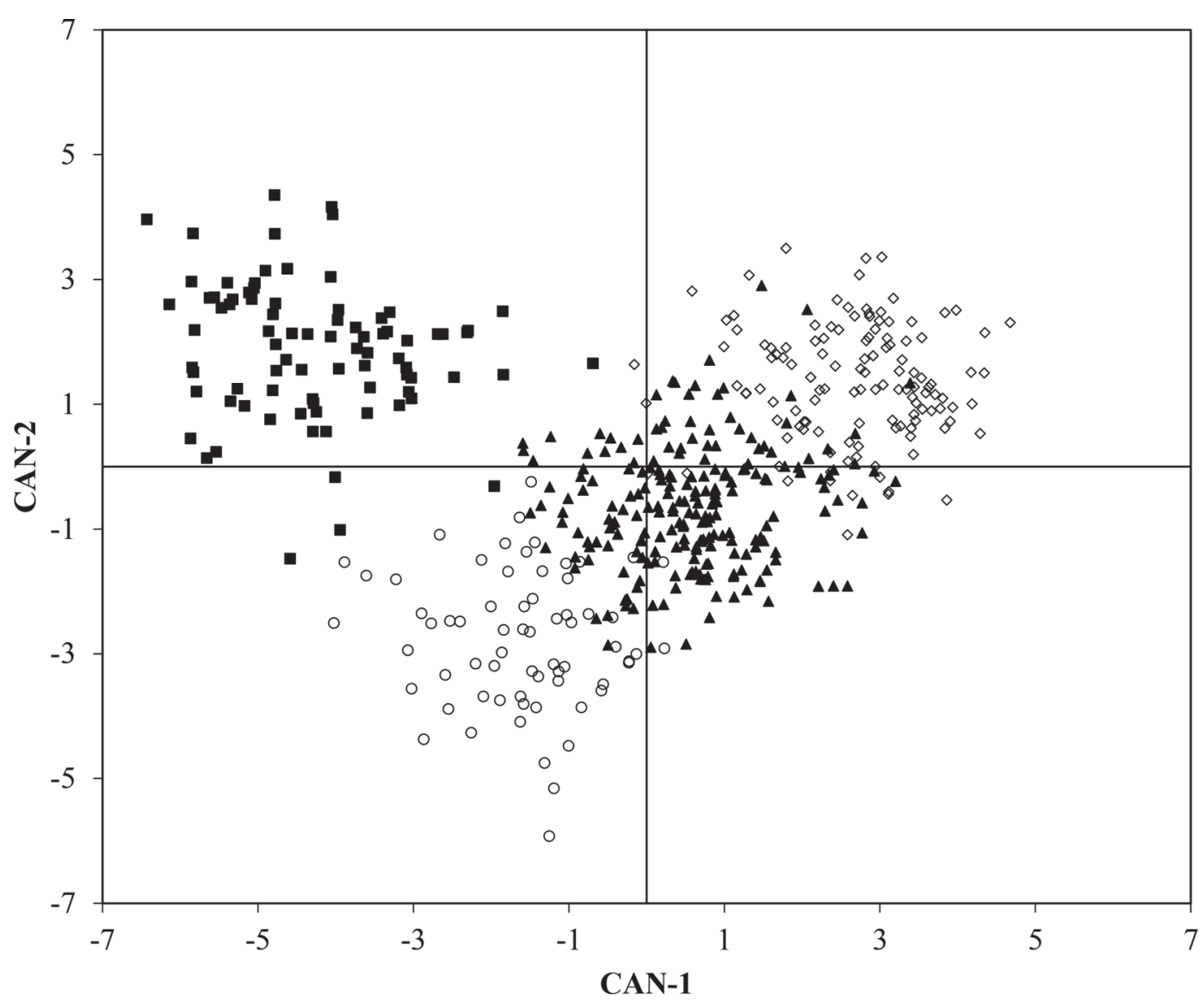

Figure 1. Scatter plot of the first canonical (CAN) variable (x-axis) versus the second canonical variable (y-axis) in early coagulating [i.e., rennet coagulation time $(\mathrm{RCT})<10 \mathrm{~min}]$ milk samples $(\diamond)$, mid-coagulating (i.e., $10 \mathrm{~min} \leq \mathrm{RCT} \leq 20 \mathrm{~min})$ milk samples $(\mathbf{\Delta})$, late-coagulating (i.e., $20 \mathrm{~min}<\mathrm{RCT} \leq 30 \mathrm{~min})$ milk samples $(\bigcirc)$, and noncoagulating (i.e., RCT $>30 \mathrm{~min})$ milk samples $(\mathbf{\square})$.

For individual cow milk samples, similar numbers of \#L have been used for RCT, TA, and pH (De Marchi et al., 2009; Visentin et al., 2015) and $\mathrm{k}_{20}$ (Visentin et al., 2015) prediction models; however, lower \#L factors have been reported for RCT and $\mathrm{a}_{30}$ (3-8; Dal Zotto et al., 2008) and TA (6; Toffanin et al., 2015) prediction equations. For cow milk, some authors have reported similar $\mathrm{R}_{\mathrm{CV}}^{2}$ for RCT and $\mathrm{a}_{30}$ (Dal Zotto et al., 2008; Visentin et al., 2015), TA (De Marchi et al., 2009), and pH (De Marchi et al., 2009; Visentin et al., 2015) predictions; however, other authors have achieved in cow milk higher $\mathrm{R}_{\mathrm{CV}}^{2}$ for RCT (0.62-0.79; De Marchi et al., 2009; Visentin et al., 2015), $\mathrm{k}_{20}$ (0.59; Visentin et al., 2015), and TA (0.86 and 0.96; Toffanin et al., 2015; Calamari et al., 2016) models. In addition, Visentin et al. (2015) reported similar $\mathrm{R}_{\mathrm{ExV}}^{2}$ and RPD for $\mathrm{a}_{30}$ and $\mathrm{pH}$, and higher values for $\mathrm{RCT}\left(\mathrm{R}_{\mathrm{ExV}}^{2}=0.55\right.$; $\mathrm{RPD}=$ $1.49)$ and $\mathrm{k}_{20}\left(\mathrm{R}_{\mathrm{ExV}}^{2}=0.51 ; \mathrm{RPD}=1.43\right)$ in external validation.

The accuracy of the prediction models for milk coagulation and acidity traits reported in the present study did not permit to use the sole FT-MIR spectroscopy for the determination of these milk quality traits. Such a limitation may represent an obstacle, for example, to the implementation of milk quality payment schemes using FT-MIR equations, in which the accuracy of predicting any milk phenotype should equate (ideally) to 1. However, from a genetic point of view, the use of the predicted phenotypes may represent a viable solution to the difficulty of collecting phenotypes at population level to estimate precise (co)variance components. In addition, the results of the CDA also suggest that exploitable information on milk rennet reactivity exists in the spectra (Figure 1), which has potentially great implication for the dairy industry specialized in cheese manufacturing. As we can observe in Figure 1, prediction models developed permit the segregation of milk according to its coagulation aptitude, where noncoagulated milk samples are clearly separated from coagulating milk. Furthermore, from a practical point of view, the combination between milk coagulation and acidity traits into a unique technological index may be 
a solution to genetically improve milk technological properties, as proposed by van Kaam et al. (2015) on the Italian Holstein-Friesian dairy cattle population. Finally, to our knowledge no studies have investigated the effect of milk coagulation and acidity traits on buffalo milk cheese yield and quality, although an association between these traits is expected, as favorable milk coagulation and acidity traits (i.e., short RCT, strong $\mathrm{a}_{30}$, and low $\mathrm{pH}$ ) are associated with improved cheese yield (Pretto et al., 2013).

In conclusion, our prediction models for coagulation and acidity traits in buffalo milk were in agreement with prediction models developed using bovine milk. The FT-MIR prediction models cannot be proposed as a valid substitution of the reference laboratory methodologies to measure coagulation and acidity traits in buffalo milk; however, exploitable information on milk coagulating ability is present in the FT-MIR spectra, which could represent a tool for the dairy industry to improve the efficiency of the cheesemaking process.

\section{REFERENCES}

Abd El-Salam, M. H., and S. El-Shibiny. 2011. A comprehensive review on the composition and properties of buffalo milk. Dairy Sci. Technol. 91:663-699.

Ariota, B., G. Campanile, A. Potena, R. Napolano, B. Gasparrini, G. L. Neglia, and R. Di Palo. 2007. Ca and P in buffalo milk: Curd yield and milk clotting parameters. Ital. J. Anim. Sci. 6(Suppl. 1):497-499.

Barile, V. L., C. Tripaldi, L. Pizzoferrato, C. Pacelli, G. Palocci, S. Allegrini, M. Maschio, M. Mattera, P. Manzi, and A. Borghese. 2007. Effect of different diets on milk yield and quality of lactating buffaloes: maize versus sorghum silage. Ital. J. Anim. Sci. 6:520-523.

Bastin, C., L. Théron, A. Lainé, and N. Gengler. 2016. On the role of mid-infrared predicted phenotypes in fertility and health dairy breeding programs. J. Dairy Sci. 99:4080-4094.

Calamari, L., L. Gobbi, and P. Bani. 2016. Improving the prediction ability of FT-MIR spectroscopy to assess titratable acidity in cow's milk. Food Chem. 192:477-484.

Cecchinato, A., M. Penasa, C. Cipolat Gotet, M. De Marchi, and G. Bittante. 2012. Short communication: Factors affecting coagulation properties of Mediterranean buffalo milk. J. Dairy Sci. 95:1709-1713.

Dal Zotto, R., M. De Marchi, A. Cecchinato, M. Penasa, M. Cassandro, P. Carnier, L. Gallo, and G. Bittante. 2008. Reproducibility and repeatability of measures of milk coagulation properties and predictive ability of mid-infrared reflectance spectroscopy. J. Dairy Sci. 91:4103-4112.
De Marchi, M., C. C. Fagan, C. P. O'Donnell, A. Cecchinato, R. Dal Zotto, M. Cassandro, M. Penasa, and G. Bittante. 2009. Prediction of coagulation properties, titratable acidity, and $\mathrm{pH}$ of bovine milk using mid-infrared spectroscopy. J. Dairy Sci. 92:423-432.

De Marchi, M., V. Toffanin, M. Cassandro, and M. Penasa. 2014. Invited review: Mid-infrared spectroscopy as phenotyping tool for milk traits. J. Dairy Sci. 97:1171-1186.

FAOSTAT. 2017. Livestock Primary. Accessed Jan. 12, 2017. http:// www.fao.org/faostat/en/\#data/QL

Liotta, L., V. Chiofalo, V. Lo Presti, A. Vassallo, G. Dalfino, and A. Zumbo. 2015. The influence of two different breeding systems on quality and clotting properties of milk from dairy buffaloes reared in Sicily (Italy). Ital. J. Anim. Sci. 14:508-511.

Manuelian, C. L., S. Currò, M. Penasa, M. Cassandro, and M. De Marchi. 2017. Characterization of major and trace minerals, fatty acid composition, and cholesterol content of Protected Designation of Origin cheeses. J. Dairy Sci. 100:3384-3395.

McMahon, D. J., and R. J. Brown. 1982. Evaluation of formagraph for comparing rennet solutions. J. Dairy Sci. 65:1639-1642.

McParland, S., and D. P. Berry. 2016. The potential of Fourier transform infrared spectroscopy of milk samples to predict energy intake and efficiency in dairy cows. J. Dairy Sci. 99:4056-4070.

Penasa, M., M. De Marchi, S. Ton, L. Ancilotto, and M. Cassandro. 2015. Reproducibility and repeatability of milk coagulation properties predicted by mid-infrared spectroscopy. Int. Dairy J. 47:1-5.

Pretto, D., M. De Marchi, M. Penasa, and M. Cassandro. 2013. Effect of milk composition and coagulation traits on Grana Padano cheese yield under field conditions. J. Dairy Res. 80:1-5.

Toffanin, V., M. De Marchi, N. Lopez-Villalobos, and M. Cassandro. 2015. Effectiveness of mid-infrared spectroscopy for prediction of the contents of calcium and phosphorus, and titratable acidity of milk and their relationship with milk quality and coagulation properties. Int. Dairy J. 41:68-73.

Tripaldi, C., S. Amatiste, G. Giangolini, G. Palocci, and A. Borghese. 2013. Milk quality and products. Pages 232-259 in Buffalo Livestock and Products. A. Borghese, ed. CRA (Consiglio per la ricerca in agricoltura), Rome, Italy.

van Kaam, J. B. C. H. M., M. Battagin, R. Finocchiaro, D. Pretto, M. Penasa, M. De Marchi, and M. Cassandro. 2015. Breeding value estimation for milk coagulation properties in the Italian Holstein Friesian bull population. Interbull Bull. 49:61-63.

Visentin, G., A. McDermott, S. McParland, D. P. Berry, O. A. Kenny, A. Brodkorb, M. A. Fenelon, and M. De Marchi. 2015. Prediction of bovine milk technological traits from mid-infrared spectroscopy analysis in dairy cows. J. Dairy Sci. 98:6620-6629.

Visentin, G., M. Penasa, P. Gottardo, M. Cassandro, and M. De Marchi. 2016. Predictive ability of mid-infrared spectroscopy for major mineral composition and coagulation traits of bovine milk by using the uninformative variable selection algorithm. J. Dairy Sci. 99:8137-8145.

Williams, P. 2007. Statistical terms for evaluation of accuracy and precision. Pages 5-1 to 5-17 in Near Infrared Technology-Getting the Best out of Light. 5.0 ed., PDK Grain, Nanaimo, BC, and Winnipeg, MB, Canada.

Zicarelli, L. 2004. Buffalo milk: Its properties, dairy yield and mozzarella production. Vet. Res. Commun. 28:127-135. 